\title{
Curcumin loaded sub-30 nm targeting therapeutic lipid nanoparticles for synergistically blocking nasopharyngeal cancer growth and metastasis
}

Haiming Luo ${ }^{1,2^{*}+} \mathbb{B}$, Lisen $\mathrm{Lu}^{1,2+}, \mathrm{Ni}^{\mathrm{Li}} \mathrm{u}^{1,2}$, Qingqing $\mathrm{Li}^{1,2}$, Xiaoquan Yang ${ }^{1,2}$ and Zhihong Zhang ${ }^{1,2^{*}}$

\begin{abstract}
Systemic chemotherapy is still the primary treatment for advanced-stage nasopharyngeal carcinoma (NPC), but only limited therapeutic success has been achieved in the past decade because of drug resistance and systemic toxicity. Curcumin (Cur) is an effective alternative to chemotherapeutics because it showed remarkable therapeutic potential in the treatment of NPC. However, lack of tissue specificity and poor penetration in solid tumors are the major obstacles to effective therapy. Therefore, in this work, a self-assembled sub-30 nm therapeutic lipid nanoparticle loaded with Cur, named as Cur@a-NTP-LN, was constructed, specifically targeting scavenger receptor class B member 1 (SRB1) and enhancing its therapeutic effects on NPC in vivo. Our results showed that Cur@a-NTP-LNs were effective and superior to free Cur on NPC cell-specific targeting, suppressing cell proliferation and inducing cell apoptosis. In vivo and ex vivo optical imaging revealed that Cur@a-NTP-LNs exerted high targeting efficiency, specifically accumulating in NPC xenograft tumors and delivering Cur into the tumor center after systemic administration. Furthermore, Cur@aNTP-LNs exhibited a remarkable inhibitory effect on the growth of NPC subcutaneous tumors, with over 71 and $47 \%$ inhibition compared to Cur- and a-NTP-LNs-treated groups, respectively. In addition, Cur@a-NTP-LNs almost blocked NPC metastasis in a lung metastasis model of NPC and significantly improved the survival rate. Thus, the sub-30 nm Cur@a-NTP-LNs enhanced the solubility of Cur and demonstrated the ability of targeted Cur delivery into the center of the solid NPC tumor, performing synergistic inhibitory effects on the growth of NPC tumor and its metastasis with high efficiency.
\end{abstract}

Keywords: Nasopharyngeal carcinoma, Targeted therapy, Curcumin, Peptide, Lipid nanoparticles

*Correspondence: hemluo@hust.edu.cn; czyzzh@mail.hust.edu.cn

${ }^{\dagger}$ Haiming Luo and Lisen Lu contributed equally to this work

1 Britton Chance Center for Biomedical Photonics, Wuhan National

Laboratory for Optoelectronics-Huazhong University of Science and Technology, Wuhan 430074, China

Full list of author information is available at the end of the article

\begin{abstract}
Introduction
Nasopharyngeal carcinoma (NPC) is a malignant head and neck cancer with high incidence in Southern China and Southeast Asia [1, 2]. NPC is characterized by an aggressive feature, poor diagnosis, and limited therapeutic opportunities [2,3]. The outcome of metastatic NPC is still disappointing, and failure on distant metastasis remains a significant challenge. Palliative chemotherapy plays a significant role in advanced or metastatic NPC and could potentially prolong the survival of patients with advanced NPC [3]. Current standard treatments
\end{abstract} permits use, sharing, adaptation, distribution and reproduction in any medium or format, as long as you give appropriate credit to the original author(s) and the source, provide a link to the Creative Commons licence, and indicate if changes were made. The images or other third party material in this article are included in the article's Creative Commons licence, unless indicated otherwise in a credit line to the material. If material is not included in the article's Creative Commons licence and your intended use is not permitted by statutory regulation or exceeds the permitted use, you will need to obtain permission directly from the copyright holder. To view a copy of this licence, visit http://creativecommons.org/licenses/by/4.0/. The Creative Commons Public Domain Dedication waiver (http://creativeco mmons.org/publicdomain/zero/1.0/) applies to the data made available in this article, unless otherwise stated in a credit line to the data. 
for advanced NPC involve platinum-based doublet chemotherapy consisting of cisplatin/carboplatin plus gemcitabine, paclitaxel, or 5-FU, which act on cell death effectors to induce cell apoptosis and inhibit cell survival of cancer cells [4]. Although these chemotherapeutic drugs have the advantages of rapid action and ready availability, the overall survival of NPC patients is far from satisfactory and side effects are intolerable to most patients [5]. Targeted therapies on epidermal growth factor receptor (EGFR) and vascular endothelial growth factor receptor (VEGFR) have been tested in NPC patients in clinical practice according to the molecular biological characteristics of NPC [6]. Targeting a single pathway usually fails to achieve an adequate diagnosis and effective treatment due to the inherent complexity and heterogeneity of cancer [7, 8]. Unlike other chemotherapeutic agents, Curcumin (Cur) is well tolerated and exhibits specific anti-cancer, antioxidant, and antiinflammatory effects, which are mediated through the regulation of numerous targets such as nuclear factor (NF-kB), transcription factor activator protein-1 (AP-1), and tumor-associated growth factors [9]. Many preclinical studies demonstrated that Cur can be more effective than a single pathway-targeted anti-cancer drug thanks to its pleiotropic properties [10]. Unfortunately, the poor pharmacokinetics and poor bioavailability of Cur in vivo hinder its clinical translation.

Drug delivery systems are designed to provide localized or targeted delivery of chemotherapeutic agents, resulting in an efficient approach for improving the solubility and bioavailability of Cur [11-13]. Various drug delivery carriers such as liposomes, polymeric micelles, and lipid nanoparticles have been reported to successfully encapsulate Cur to increase its solubility, thus enhancing its bioavailability and therapeutic effects $[14,15]$. These Cur nanoformulations have different characteristics, tailored by modulating the mechanisms of inducing cell death [16-18]. Although they offer various advantages for effective chemotherapy, lack of tissue and cell specificity is still a significant obstacle [14]. Furthermore, most of these conventional nanoparticles are generally over $50 \mathrm{~nm}$ in size after drug encapsulation, thus, the penetration into solid tumor tissues (e.g. pancreatic cancer and NPC) is difficult, making difficult the achievement of satisfactory treatment effects [19]. In our previous report, a hybrid peptide was designed by the fusion of an amphipathic $\alpha$-helical peptide with an NPC-specific therapeutic peptide, to interact with phospholipids, and it was selfassembled into sub-30-nm lipid nanoparticles (named as $\alpha$-NTP-LNs) that exhibited promising therapeutic effects on NPC tumors and metastases [20]. In this work, Cur was encapsulated into $\alpha$-NTP-LNs to achieve a bettertargeted therapeutic modality, and the newly formed
Cur@ $\alpha-N T P-L N s$ could precisely deliver Cur to tumor sites with enhanced treatment efficacy.

Therefore, the aim of this work was to develop a therapeutic nanoparticle formulation combining the specific NPC targeting ability of $\alpha$-NTP-LNs and anticancer effects of Cur, to form an attractive agent for delaying NPC cancer onset and progression. Cur was encapsulated into the lipid nanoparticles $\alpha$-NTP-LNs, and the final preparation Cur@ $\alpha$-NTP-LNs was optimized to ensure its stability and NPC-specific targeting ability. Importantly, the targeted delivery properties of Cur by Cur@ $\alpha-N T P-L N s$, in vivo pharmacokinetics and therapeutic effects of Cur@ @-NTP-LNs on the growth of NPC subcutaneous tumor and its metastasis were evaluated.

\section{Materials and methods Materials}

1,2-Dimyristoyl-sn-glycero-3-phosphocholine (DMPC) was purchased from Avanti Polar Lipids Inc. (Alabaster, Alabama, USA). Hoechst 33,342, free Cur, and DSPEPEG2000 were purchased from Sigma-Aldrich Co. (St. Louis, MO, USA). DiR-BOA was synthesized according to our procedure previously described [21, 22]. Free $\alpha$-NTP with the sequence FAEKFKEAVKDYFAKFWDGSGLTVSPWYLTVSPWY was purchased from Shanghai Apeptide Co., Ltd. (Shanghai, China). APC Annexin V Apoptosis Detection Kit with propidium iodide (PI) was purchased from Biolegend (Pharmingen, San Diego, CA, USA).

\section{Preparation of Cur@a-NTP-LNs and Cur(DiR-BOA)@a-NTP-LNs}

A similar procedure used to synthesize $\alpha$-NTP-LNs previously described was used to prepare Cur@ $\alpha-N T P-L N s$ [20]. The mixture of DMPC $(3 \mu \mathrm{M})$, DSPE-PEG2000 $(0.7 \mu \mathrm{M})$, and Cur $(0.7 \mu \mathrm{M})$ in chloroform was dried under nitrogen to form a uniform lipid film. After adding $1 \mathrm{ml}$ phosphate-buffered saline (PBS), the mixture was sonicated at $48^{\circ} \mathrm{C}$ for $1 \mathrm{~h}$ to form a lipid emulsion. PBS containing different amounts of $\alpha$-NTP peptide was added into the lipid emulsion to make Cur@ $\alpha-N T P-L N s$ by an overnight incubation at $4^{\circ} \mathrm{C}$. As regard the preparation of the nanoparticles Cur(DiR-BOA)@ $\alpha-N T P-L N s$, which were core loaded with DiR-BOA, the only difference in the above-described protocol was the first step, in which $0.2 \mu \mathrm{M}$ of DiR-BOA was mixed with DMPC, DSPE-PEG2000, and Cur in chloroform. The nanoparticles were concentrated using a concentrator tube with a $30-\mathrm{kDa}$ molecular weight cutoff (Millipore, USA). The quantification of the proteins in the nanoparticles was evaluated using an mp06667-CBQCA protein quantitation kit (Invitrogen Corporation, California, CA, USA) 
and Pierce Modified Lowry Protein Assay Kit (Thermo Fisher Scientific; Rockford, IL, USA).

\section{Morphology, size, and spectrum of the NPs}

The morphology and size of Cur@ $\alpha-N T P-L N s$ were evaluated using a Tecnai $\mathrm{G}^{2} 20$ U-Twin transmission electron microscope (FEI Company, USA). The particle size distribution and zeta potential were measured using a dynamic light scattering (photon correlation spectroscopy) on a Zetasizer Nano-ZS90 system (Malvern Instruments, Worcestershire, UK). The spectrum of free Cur and Cur@ $\alpha-$ NTP-LNs was measured with a spectrophotometer (Lambda 35; PerkinElmer, Waltham MA, USA).

\section{Stability evaluation}

Cur(DiR-BOA)@ $\alpha-N T P-L N s$ were run on a $8 \%$ seminative SDS-polyacrylamide gel electrophoresis (SDSPAGE) to ensure whether the fluorescent band of free Cur matched with DiR-BOA with a custom-made optical fluorescence imaging system [23, 24]. The nanoparticles were incubated with PBS, $10 \% \mathrm{FBS}, 10 \%$ plasma, and $5 \%$ Tween- 20 at $37^{\circ} \mathrm{C}$ for $3 \mathrm{~h}$ before running the gels.

\section{In vitro drug release by Cur@a-NTP-LNs}

To measure the release kinetics of Cur by Cur@ $\alpha-N T P-$ LNs, 8 aliquots of $200 \mu \mathrm{L}$ Cur@ $\alpha-N T P-L N s$ solution were placed into 8 tubes. After incubation for $0,3,6,12,15$, 24,48 , and $72 \mathrm{~h}$ at $37^{\circ} \mathrm{C}$, each tube was centrifuged using a table-top centrifuge (ATT-101, HITECH Co., Ltd., Tokyo, Japan) at 10,000 g for $2 \mathrm{~min}$. The supernatants were transferred to 96-well plates and measured with a fluorometric imaging plate reader (Flexstation 3; Molecular Devices Corp., Sunnyvale, CA, USA).

\section{Cell culture}

Human nasopharyngeal cancer cells $5-8 \mathrm{~F}$ were donated by Prof. Mu-Sheng Zeng (Sun Yat-sen University Cancer Center, Guangzhou, China). mRFP-5-8F cells stably expressing the monomer red fluorescent protein mRFP were screened for whole-body fluorescence imaging of tumor models [25]. 5-8F and mRFP-5-8F cells were cultured in RPMI-1640 (Invitrogen Life Technologies, Carlsbad, USA) supplemented with $10 \%$ fetal bovine serum (FBS, Life Technologies), $100 \mathrm{U} / \mathrm{ml}$ penicillin, and $0.1 \mathrm{mg} / \mathrm{ml}$ streptomycin, and incubated at $37^{\circ} \mathrm{C}$ under $5 \%$ $\mathrm{CO}_{2}$.

\section{Confocal imaging}

$1 \times 10^{4} 5$-8F cells were seeded into each well of an 8-well cover glass-bottom chamber (Thermo Scientific, Holtsville, NY, USA) for confocal imaging. Cur@ $\alpha-N T P-L N s$ (Cur concentration, $2.5 \mu \mathrm{M}$ ) were incubated with the cells at $37^{\circ} \mathrm{C}$ for $3 \mathrm{~h}$. After staining with Hoechst 33,342 for $5 \mathrm{~min}$, cells were washed twice with PBS and the fluorescence signals were observed using a laser confocal scanning microscope (LSM710, Carl Zeiss), at an excitation wavelength of $405 \mathrm{~nm}$ for Hoechst 33,342 and $488 \mathrm{~nm}$ for Cur.

\section{Cell proliferation and cell killing detection}

5 -8F cells were seeded into 48 -well plates $\left(2 \times 10^{4} /\right.$ well $)$ for flow cytometry analysis. Cur@ $\alpha-N T P-L N s$ at the concentration of 10, 25, 50, 75, and $100 \mu \mathrm{M}$ (Cur concentration) were separately incubated with cells at $37^{\circ} \mathrm{C}$ for $3 \mathrm{~h}$. The fluorescence intensity of cells was examined using a microcapillary flow cytometer (Guava EasyCyte8HT, EMD Millipore Corporation, Billerica, MA, USA) at an excitation wavelength of $488 \mathrm{~nm}$ for Cur (525/30 emission filter).

5-8F cells were seeded into 24-well plates at a density of approximately $5 \times 10^{4}$ cells per well. After $24 \mathrm{~h}$ incubation with Cur@ $\alpha$-NTP-LNs and Cur at various Cur concentrations $(10,25,50,75,100,150$, and $200 \mu \mathrm{M})$ and $\alpha$-NTP-LNs at various peptide concentrations $(20,50$, $100,150,200,350$, and $400 \mu \mathrm{M})$, the cells were imaged using a microscope (IX71, Olympus) and the cell viability was assessed by the methyl tetrazolium salt (MTS) assay (Cell Titer 96TM Aqueous; Promega, Madison, WI, USA).

The toxicity of the nanoparticles was evaluated as follows. 5-8F cells were incubated with Cur@ @-NTP-LNs and Cur at various Cur concentrations $(25,50,100,150$, 200 , and $250 \mu \mathrm{M}$ ) or Cur@ $\alpha-N T P-L N s$ and $\alpha-N T P-L N s$ at various peptide concentrations $(50,100,200,300,400$, and $500 \mu \mathrm{M}$ ) for $24 \mathrm{~h}$, and stained with PI for flow cytometry experiments.

As regard cell apoptosis detection, 5-8F cells were incubated with $100 \mu \mathrm{M}$ free Cur, Cur@ $\alpha-N T P-L N s(100 \mu \mathrm{M}$ Cur, $200 \mu \mathrm{M}$ peptides) or peptide equivalent $\alpha$-NTP-LNs (200 $\mu \mathrm{M}$ peptides) for $24 \mathrm{~h}$ and then stained with APCAnnexin V and PI for flow cytometry analysis.

\section{Cell wound healing assay and clonal inhibition assay}

5 -8F cells were seeded into 6 -well plates $\left(5 \times 10^{5} /\right.$ well $)$ for $24 \mathrm{~h}$. The cells were scratched with a pipette tip and treated with $50 \mu \mathrm{M}$ free Cur, Cur equivalent Cur@ $\alpha$ NTP-LNs $(50 \mu \mathrm{M}$ Cur, $100 \mu \mathrm{M}$ peptides), or peptide equivalent $\alpha$-NTP-LNs (100 $\mu \mathrm{M}$ peptides). After $24 \mathrm{~h}$, cell migration was evaluated by microscopy (IX71, Olympus) equipped with a $4 \times$ objective.

As regard the colony formation assay, 6-well plates were coated with $2 \mathrm{~mL} 0.6 \%$ soft agar in RPMI 1640 medium supplemented with $10 \%$ FBS. $5-8$ F cells were seeded into plates with $2 \mathrm{~mL} 0.3 \%$ soft agar in RPMI 1640 medium supplemented with $10 \%$ FBS and $25 \mu \mathrm{M}$ free Cur, Cur equivalent Cur@ $\alpha-N T P-L N s(25 \mu \mathrm{M}$ Cur, 50 
$\mu \mathrm{M}$ peptides) and peptide equivalent $\alpha$-NTP-LNs (50 $\mu \mathrm{M}$ peptides) and incubated for 14 days at $37{ }^{\circ} \mathrm{C}$ under $5 \%$ $\mathrm{CO}_{2}$. The culture medium was changed every two days. The colonies were imaged by microscopy (IX71, Olympus) equipped with a $4 \times$ objective, and their diameters above 50 pixels were considered positive.

\section{In vivo and ex vivo fluorescence imaging}

All animal studies were performed in compliance with the protocols approved by the Hubei Provincial Animal Care and Use Committee and with the practical guidelines of the Animal Experimentation Ethics Committee of the Huazhong University of Science and Technology. A total of $2 \times 10^{6} 5-8 \mathrm{~F}$ cells were subcutaneously implanted into the rear leg of the mice. When tumors reached a diameter of $5-8 \mathrm{~mm}$ ( 2 to 3 weeks after implantation), $200 \mathrm{nmol}$ Cur(DiR-BOA)@ $\alpha-N T P-L N s$ or (DiRBOA)@ $\alpha-N T P-L N s$ were intravenously injected into tumor-bearing mice. In vivo and ex vivo fluorescence imaging of the mice and tissues was performed using a custom-made whole-body optical imaging system [23, 24]. The fluorescence signals of DiR-BOA were acquired using a near-infrared filter set (excitation: 716/40 nm; emission: 775/46 nm) and calibrated with an autofluorescence background filter set (excitation: 562/40 nm; emission: 775/46 nm). The fluorescence images of mRFP were acquired using a red filter set (excitation: $469 / 35 \mathrm{~nm}$; emission: 562/40 nm) and calibrated with an autofluorescence background filter set (excitation: 469/35 nm; emission: 655/40 nm).

\section{Fluorescence analysis of frozen slices}

5-8F tumor-bearing mice were sacrificed by cervical dislocation after the last imaging and the tumors were collected and frozen. The tumor was cut into $10 \mu \mathrm{m}$-thick sections using a Shandon FSE cryotome (Leica CM1900, Germany), and the slices were stained by DAPI and imaged using spinning disk confocal microscopy (SDCM, PerkinElmer) using $488 \mathrm{~nm}$ excitation and $640 \mathrm{~nm}$ emission wavelength and $10 \times$ objective. All data were processed using Matlab and Image J.

\section{Blood clearance kinetics}

Five normal nude mice were used as one group to test blood clearance of Cur(DiR-BOA)@ $\alpha-N T P-L N s$ and (DiR-BOA)@ $\alpha-N T P-L N s$. Blood samples were collected from the orbital sinus at different time points post-injection $(10 \mathrm{~min}$ to $48 \mathrm{~h}$ ) of the nanoparticles. The fluorescence intensity of DiR-BOA in the blood samples was detected using a spectrophotometer (Lambda 35; PerkinElmer, Waltham MA, USA) and recorded per milligram of blood.
Inhibitory effect of Cur@a-NTP-LNs on tumor growth

5-8F subcutaneous tumor-bearing mice were divided into four groups on day 13 after tumor cell implantation. Each group contained five mice, and the mice were treated with an intravenous injection of PBS and 125 nmol free Cur, Cur equivalent Cur@ $\alpha-N T P-L N s$ (125 nmol Cur, $250 \mathrm{nmol}$ peptides), or peptide equivalent $\alpha$-NTP-LNs (250 nmol peptides) on day 13, 15, 17,19 , and 21 , respectively. Tumor size was measured with a caliper, and the volume was calculated according to the following formula: $\mathrm{V}=(\pi / 6 \times$ longest diameter $\times$ perpendicular diameter ${ }^{2}$ ).

\section{Histopathological analyses}

Lung metastatic tumors were collected and fixed in a $4 \%$ paraformaldehyde solution. The tumors were embedded in paraffin, sectioned, and stained with hematoxylin and eosin (H\&E). The images of the H\&E staining were acquired using a Nikon A1 laser scanning confocal microscope.

\section{Hemanalysis and biochemical analyses}

Blood samples were collected from 5-8F tumor-bearing mice treated with PBS or $125 \mathrm{nmol}$ free Cur, Cur equivalent Cur@ $\alpha-N T P-L N s$ (125 nmol Cur, $250 \mathrm{nmol}$ peptides), or peptide equivalent $\alpha$-NTP-LNs $(250 \mathrm{nmol}$ peptides) on days $13,15,17,19$, and 21 . The blood cell and biochemical analyses were performed using a hematology analyzer (BC-3200, Mindray, Shenzhen, China) and an automatic biochemical analyzer (Spotchem EZ SP-4430, Arkray Inc., Kyoto, Japan), respectively.

\section{Effect of Cur@a-NTP-LNs on NPC lung metastasis and survival rate}

5-8F cells were intravenously injected into athymic nude mice $(\mathrm{nu} / \mathrm{nu})$ and randomly divided into four groups, which were treated with an intravenous injection of PBS or 125 nmol free Cur, Cur equivalent Cur@ $\alpha-N T P-L N s$ (125 nmol Cur, $250 \mathrm{nmol}$ peptides), or peptide equivalent $\alpha$-NTP-LNs (250 nmol peptides). The treatments were started on days 13,15, 17, 19 and 21 from the injection of the $5-8 \mathrm{~F}$ cells. Three mice in each group were used to perform an X-ray computed tomography scan on day 25 to detect whether pulmonary metastases occurred in mice with different treatments. After the CT scan, the mice were sacrificed, and lung tissues were collected and subjected to H\&E staining. The survival rate was monitored in the remaining 5 mice.

\section{Statistical analysis}

Statistical analysis was performed using GraphPad Prism with log-rank test. Nonparametric statistical 
tests (Kruskal-Wallis and Mann-Whitney U tests) were used to analyze the significance of the differences in the hemanalysis and biochemical parameters, and two-tailed Student's $t$-tests was used to analyze the other data. All data are expressed as mean \pm standard deviation (s.d.). Differences between or among groups were labeled as n.s. for not significant values, or * for $p<0.05$, ** for $p<0.01$, and ${ }^{* * * *}$ for $p<0.001$.

\section{Results}

\section{Characterization and drug encapsulation}

Different amounts of $\alpha$-NTP peptide (0.36 to $1.08 \mu \mathrm{mol})$ were added to DMPC lipid mixture $(3 \mu \mathrm{mol})$, Cur $(0.7 \mu \mathrm{mol})$ and DSPE-PEG2000 $(0.7 \mu \mathrm{M})$ to optimize the formulation ratio for the fabrication of Cur@ $\alpha-N T P-L N s$. The schematic diagram of Cur@ $\alpha-N T P-L N s$ is shown in Fig. 1a. When the turbid emulsion became transparent (Fig. 1b), dynamic light scattering (DLS) measurements were immediately performed. The results showed that the intensity weighted particle size of Cur@ $\alpha-N T P-L N s$ varied from 36.1 to $15.2 \mathrm{~nm}$ as the amount of $\alpha$-NTP increased from 0.36 to $0.72 \mu \mathrm{mol}$ (Additional file 1 :
Fig. S1). When the amount of $\alpha-\mathrm{NTP}$ was increased to $1.08 \mu \mathrm{mol}$, the solution became cloudy, and the size of the nanoparticle was $119.8 \mathrm{~nm}$, probably because of the excessive free Cur at high peptide/lipid molar ratio that became insoluble, leading to a lower loading capacity and cloudy emulsion. Thus, $0.72 \mu \mathrm{mol} \alpha$-NTP was used to synthesize Cur@ $\alpha$-NTP-LNs due to the ideal size of the nanoparticles and the best loading efficiency of Cur. Transmission electron microscopy (TEM) and dynamic light scattering (DLS) measurements revealed the uniform spherical form of the Cur@ $\alpha-N T P-L N s$ with a diameter of $19.8 \pm 4.2 \mathrm{~nm}$ (Fig. 1c). The absorption spectrum of Cur@ $\alpha-N T P-L N s$ confirmed that Cur was successfully loaded into the nanoparticles (Fig. 1d).

Subsequently, Cur@ $\alpha-N T P-L N s$ were mixed with an equivalent volume of $\mathrm{PBS}, 10 \% \mathrm{FBS}$ or mouse plasma to measure the stability of Cur@ $\alpha-N T P-L N s$, and incubated at 4 or $37^{\circ} \mathrm{C}$ for $3 \mathrm{~h}$ to run semi-native SDS-PAGE gels. The amount of Cur@ $\alpha-N T P-L N s$ in different treatments could be evaluated by directly detecting the fluorescence intensity of Cur in the gel once separated by electrophoresis due to the unique optical properties of Cur

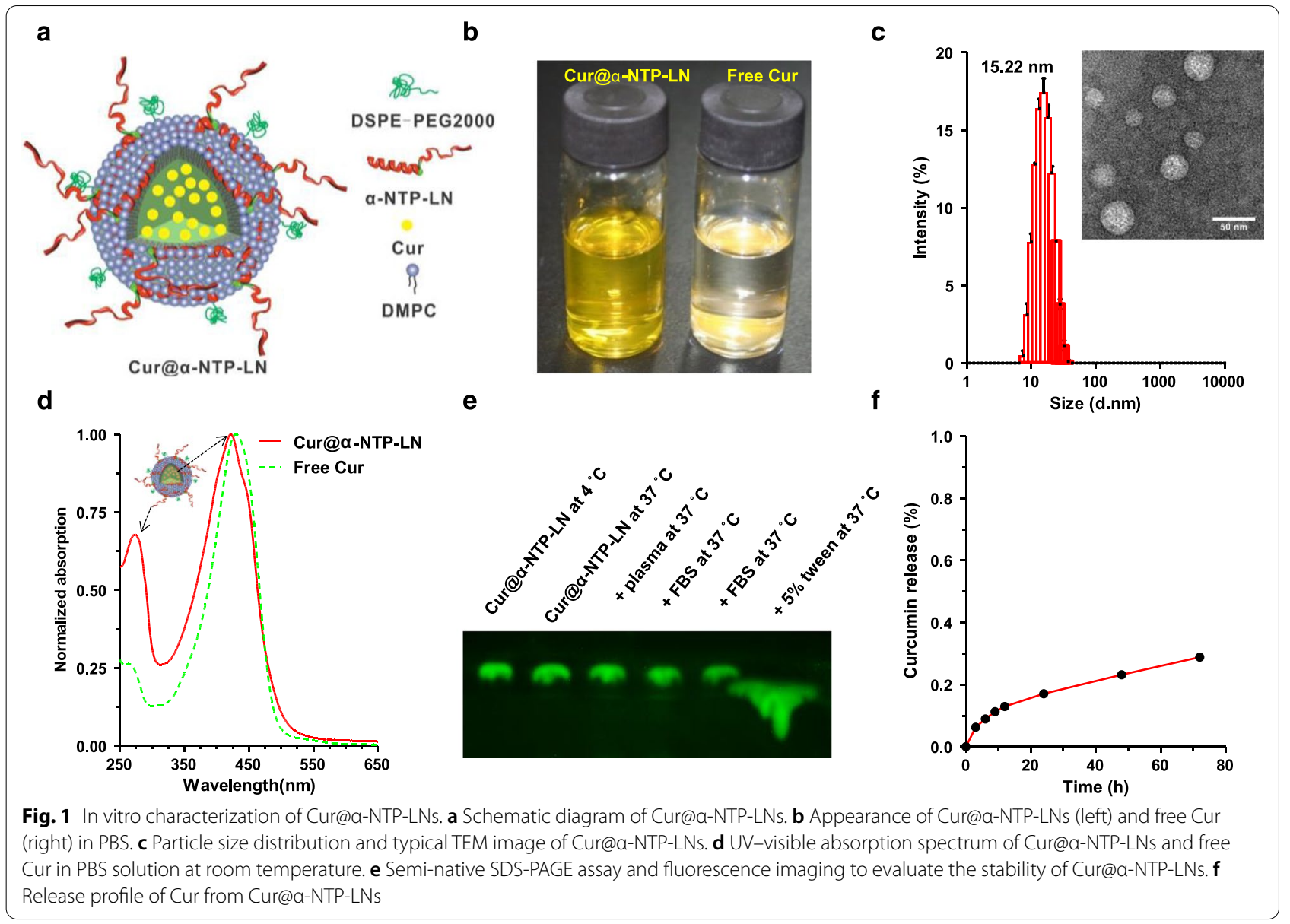


(Additional file 1: Fig. S2). Similar fluorescence intensity of Cur in control and treated samples confirmed that Cur@ $\alpha-N T P-L N s$ were stable during $3 \mathrm{~h}$ incubation in $10 \% \mathrm{FBS}$ and $10 \%$ plasma at $37^{\circ} \mathrm{C}$ (Fig. 1e). As a control, the fluorescence imaging of Cur@ $\alpha-N T P-L N s$ after dissociation with $5 \%$ Triton X-100 on the gel showed diffuse fluorescent signals of Cur (Fig. 1e). The in vitro release profile of the loaded Cur from Cur@ $\alpha-N T P-L N s$ at physiological pH is shown in Fig. 1f. Cur was released in a sustained manner, and only $30 \%$ of the total Cur was released from Cur@ $\alpha-$ NTP-LNs at 80 h of incubation.

\section{Targeted delivery of Cur@a-NTP-LNs and evaluation of its anti-cancer effects}

Confocal microscopy and flow cytometry were used to investigate the targeted delivery ability of Cur@ $\alpha-$ NTP-LNs in releasing Cur to NPC. The binding affinity of Cur@ $\alpha-N T P-L N$ and free Cur to human NPC 5-8F cells was evaluated by detecting the fluorescence of Cur.
After $3 \mathrm{~h}$ of incubation with Cur@ $\alpha-N T P-L N s$, SR-B1 ${ }^{+}$ 5-8F cells [25] displayed a strong Cur fluorescence signal mainly located in the cytoplasm (Fig. 2a). However, the fluorescence signal of free Cur in 5-8F cells was weak and located on the surface of the cell membrane, consistent with previous reports that small molecular Cur enters cells via passive diffusion [26]. Flow cytometry analysis further showed the higher uptake of Cur@ $\alpha-N T P-L N s$ at each Cur concentration compared to free Cur (Fig. 2b). The uptake efficiency of Cur@ $\alpha-N T P-L N s$ was increased in $5-8 \mathrm{~F}$ cells in a concentration-dependent manner. Cur@ $\alpha-N T P-L N s$ were more efficient in delivering Cur, with an approximate three-fivefold enhancement at various concentrations compared with free Cur (Fig. 2b). Together, the results indicated that the highly efficient delivery of Cur was due to the strong NPC-specific targeting of Cur@ $\alpha-N T P-L N$.

The concentration-dependent cytotoxicity of Cur@ $\alpha-$ NTP-LNs was further investigated on NPC cells. a

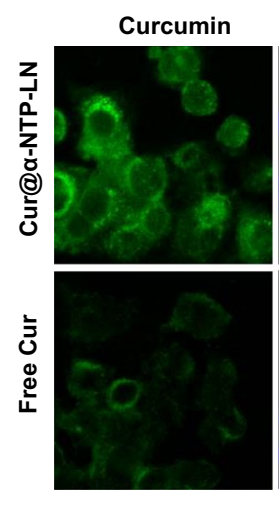

C

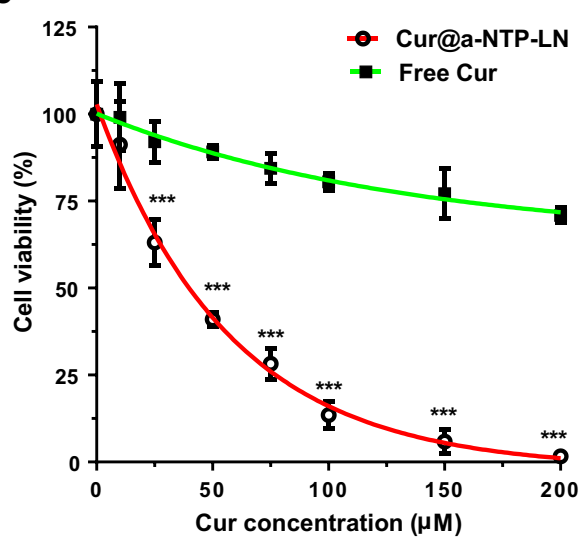

b
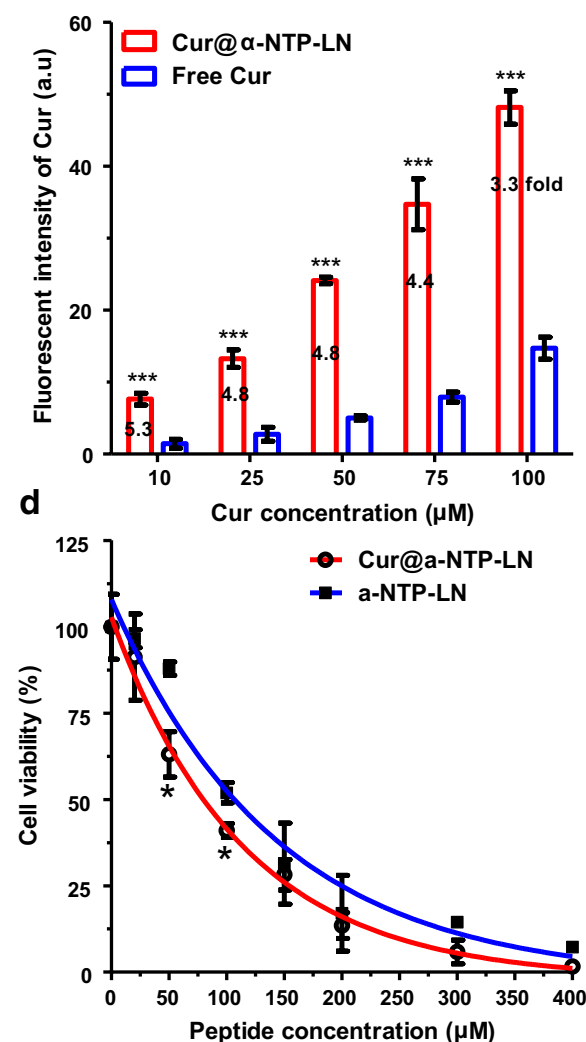

Fig. 2 NPC targeting ability and cytotoxicity of Cur@a-NTP-LNs. a Confocal images of 5-8F cells incubated with $10 \mu M$ Cur@a-NTP-LNs and free Cur. Scale bar $=20 \mu \mathrm{m}$. b Quantitative flow cytometry analysis of the fluorescence intensity of Cur in 5-8F cells treated with a serial concentration of Cur@a-NTP-LNs and free Cur for $3 \mathrm{~h}(\mathrm{n}=4)$ ).c, $\mathbf{d}$ Proliferation assay evaluating the cytotoxic effect on 5-8F cells of a serial Cur concentration of $\mathbf{c}$ free Cur and Cur@a-NTP-LNs or a serial peptide concentration of $\mathbf{d}$ Cur@a-NTP-LNs and a-NTP-LNs for $24 \mathrm{~h}(\mathrm{n} \geq 3$ ). Results are presented as mean \pm s.d. ${ }^{* * *} p<0.001$ and ${ }^{*} p<0.05$ 
Cell proliferation assay showed that the proliferation rate of $5-8 \mathrm{~F}$ cells was $41.0 \pm 2.0 \%$ when treated with $50 \mu \mathrm{M}$ (Cur concentration) Cur@ $\alpha-N T P-L N s$, while free Cur exhibited a significantly lower inhibitory effect on cell proliferation under the same conditions $(\mathrm{n} \geq 3, p<0.001$, Fig. 2c). Furthermore, Cur@ $\alpha$-NTPLNs showed a significantly higher inhibition rate on $5-8 \mathrm{~F}$ cell proliferation at 50 and $100 \mu \mathrm{M}$ of peptide concentration compared to that of $\alpha$-NTP-LNs $(n \geq 3$, $p<0.5$, Fig. $2 \mathrm{~d}$ ). After $24 \mathrm{~h}$ incubation with nanoparticles, flow cytometry analysis also showed that the death rate of $5-8 \mathrm{~F}$ cells was correlated with the concentration of the nanoparticles (Fig. 3a and b). Free Cur induced only an approximate $20 \%$ cell death even at a high concentration $(250 \mu \mathrm{M})$, which was significantly lower than that induced by Cur@ $\alpha-N T P-L N s$ in terms of cytotoxicity to $5-8 \mathrm{~F}$ cells $(\mathrm{n} \geq 8, p<0.001$, Fig. 3a). The half-maximum inhibitory concentration
$\left(\mathrm{IC}_{50}\right)$ of Cur@ $\alpha-\mathrm{NTP}-\mathrm{LNs}$ and $\alpha$-NTP-LNs associated to $5-8 \mathrm{~F}$ cells was $104.1 \pm 2.5 \mu \mathrm{M}$ and $129.6 \pm 3.7 \mu \mathrm{M}$, respectively ( $\mathrm{n} \geq 6$, Fig. 3b). Cur@ $\alpha-N T P-L N s$ exerted a significantly higher killing effect on 5-8F cells at 50 , 100 , and $200 \mu \mathrm{M}$ of peptide concentration compared to the effect of $\alpha$-NTP-LNs. The results confirmed that Cur@ $\alpha-N T P-L N s$ exerted an enhanced inhibitory effect on $5-8 \mathrm{~F}$ cells due to the potential synergistic interaction of $\alpha$-NTP-LNs combined with the anti-cancer agent Cur.

Next, 5-8F cells were incubated with $100 \mu \mathrm{M}$ free Cur or Cur@ @-NTP-LNs (100 $\mu \mathrm{M}$ Cur, $200 \mu \mathrm{M}$ peptide) or $200 \mu \mathrm{M}$ of $\alpha$-NTP-LNs for $24 \mathrm{~h}$, stained with APC Annexin $\mathrm{V}$ and PI, and subjected to flow cytometry analysis to investigate the mechanism of Cur@ $\alpha-N T P-$ LNs-induced cell death (Fig. 3c). The results showed that Cur@ $\alpha-N T P-L N s$ induced cell death in $90.0 \pm 2.6 \%$ of cells through apoptosis, with $16.3 \pm 3.3 \%$ of cells in early
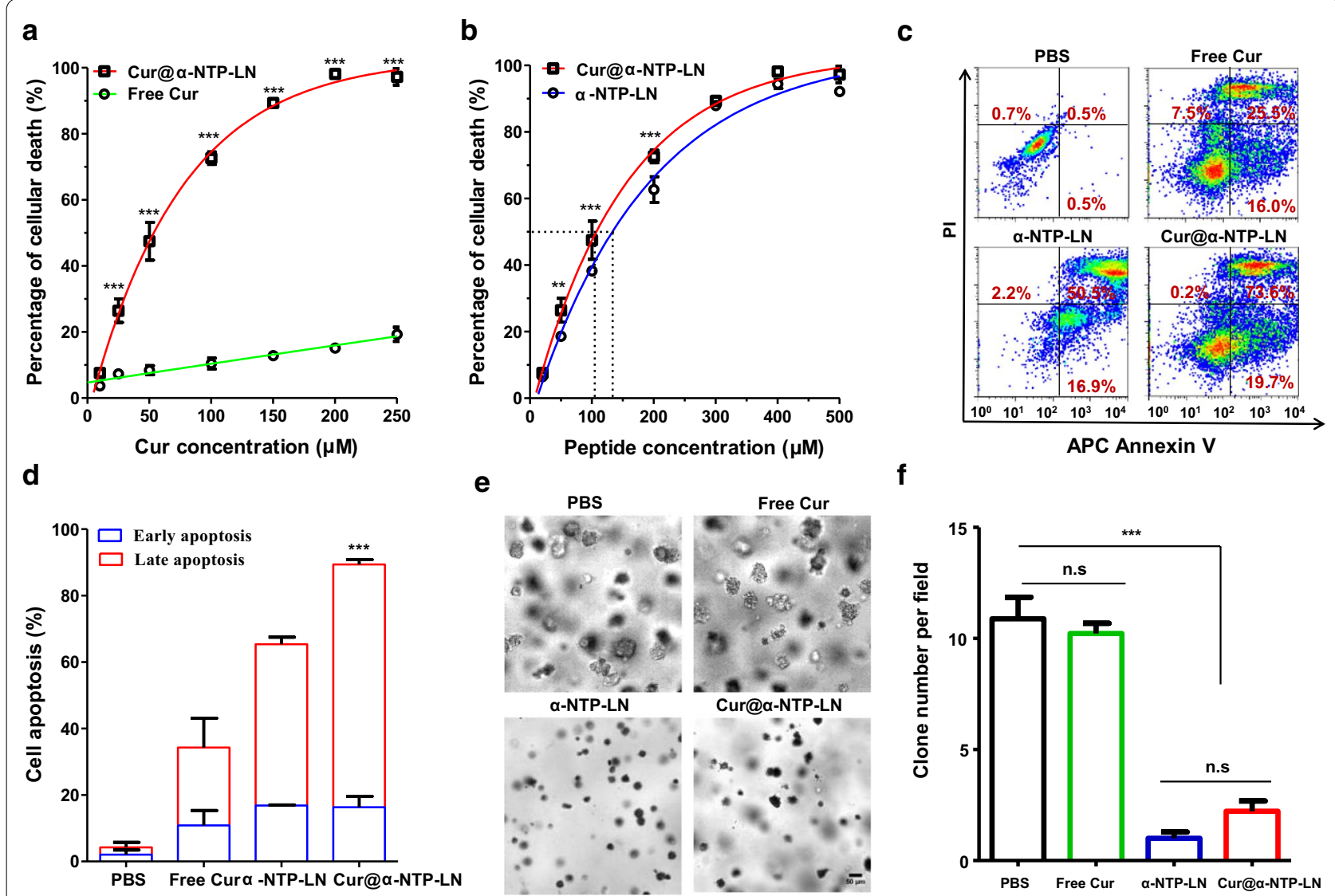

Fig. 3 Cytotoxic effect and apoptosis induced by Cur@a-NTP-LNs. a, b Quantitative flow cytometric analysis of the mortality rates of 5-8F cells treated with a serial Cur concentration of $\mathbf{a}$ free Cur and Cur@a-NTP-LNs or a serial peptide concentration of b Cur@a-NTP-LNs and a-NTP-LNs $(n \geq 6)$. c, d Quantitative flow cytometry analysis of cell apoptosis rates of 5-8F cells treated with PBS or $100 \mu$ M free Cur, Cur@a-NTP-LNs, or peptide equivalent a-NTP-LNs (200 $\mu \mathrm{M}$ peptide) for $24 \mathrm{~h}$, in which $\mathbf{c}$ is the dot plot presentation (APC-Annexin V/PI) of the representative data and $\mathbf{d}$ is the quantification of the apoptosis obtained in $\mathbf{c}$ after four independent experiments. Results are presented as mean \pm s.d. $(n=4)$. ${ }^{* * *} p<0.001$ and ${ }^{* *} p<0.01$. e Images of 5-8F cell colonies after the treatment with PBS or $25 \mu \mathrm{M}$ free Cur, Cur@a-NTP-LNs, and peptide equivalent a-NTP-LNs (50 $\mu \mathrm{M}$ peptide). $\mathbf{f}$ Quantitative analyses of the colony number per field in each treatment group of $\mathbf{e}$ 
apoptosis and $73.1 \pm 1.5 \%$ of cells in late apoptosis $(n=4$, Fig. 3d). $\alpha$-NTP-LNs induced $65.0 \pm 2.1 \%$ of apoptosis, which was consistent with our previous report [20], while only $34.3 \pm 10.3 \%$ of apoptosis was found in response to free Cur. Together, these results indicated that the combination of $\alpha$-NTP-LNs and Cur synergistically enhanced the apoptotic rate in $5-8 \mathrm{~F}$ cells.

The anti-cancer activity of Cur@ $\alpha-N T P-L N s$ was also evaluated through mobility inhibition and colony formation assay. The wound-healing assay revealed that $5-8 \mathrm{~F}$ cells treated with Cur@ $\alpha-N T P-L N s$ or peptide equivalent $\alpha$-NTP-LNs significantly reduced cell motility compared to free Cur-treated cells (Cur equivalent) (Additional file 1: Fig. S3). As regard the colony formation assay, cells treated with PBS control resulted in the formation of large colonies, while $25 \mu \mathrm{M}$ free Cur treatment resulted in less inhibitory effects on colony formation in $5-8 \mathrm{~F}$

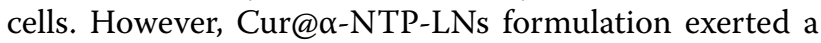
more evident reduction in colony formation compared to the effect of free Cur (Fig. 3e, f). Altogether, these results further demonstrated that Cur@ $\alpha-N T P-L N s$ exerted a high anti-cancer activity on 5-8F cells.

\section{Targeted Cur delivery of Cur@a-NTP-LNs in vivo}

The lipid-anchored near-infrared fluorophore DiRBOA was incorporated into the core of Cur@ $\alpha-N T P-$ LNs, named as Cur(DiR-BOA)@ $\alpha-N T P-L N s$, and the synthesized Cur(DiR-BOA)@ $\alpha-N T P-L N s$ was tested for its UV-vis absorbance spectra to evaluate the NPCtargeting property of Cur@ $\alpha-N T P-L N s$ in vivo (Fig. 4a). The fluorescence imaging of semi-native SDS-PAGE gels confirmed its in vitro stability (Additional file 1: Fig. S4). A pharmacokinetic study was conducted to estimate the circulation of Cur(DiR-BOA)@ $\alpha-N T P-L N s$ in the blood. The pharmacokinetic profile, obtained by fitting the data to a two-compartment model, showed that the half-life $\left(t_{1 / 2 \alpha}\right)$ of Cur(DiR-BOA)@ $\alpha-N T P-L N s$ during the initial elimination phase was $5.8 \mathrm{~min}$, and its half-life $\left(t_{1 / 2 \beta}\right)$ in the terminal elimination phase was

\section{a}

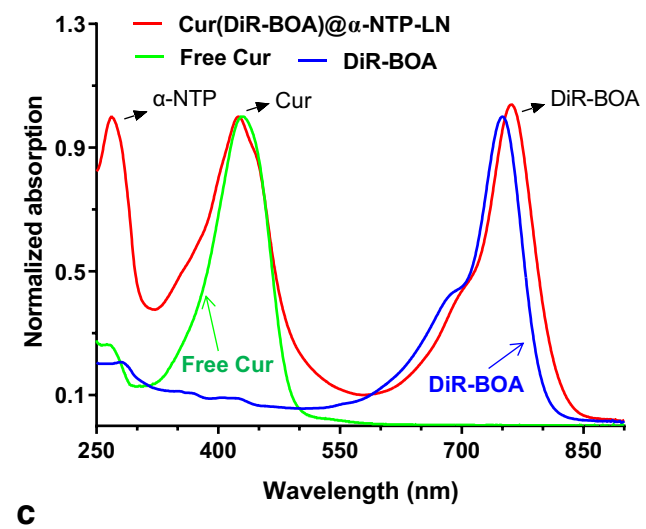

C

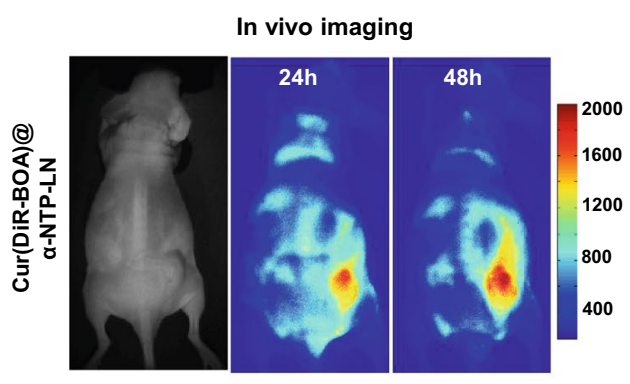

b

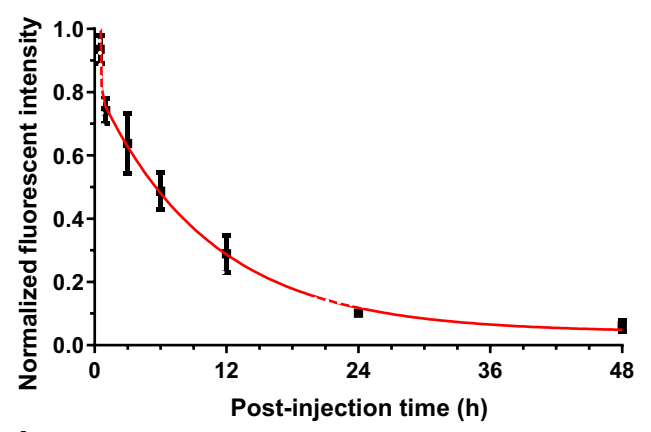

d
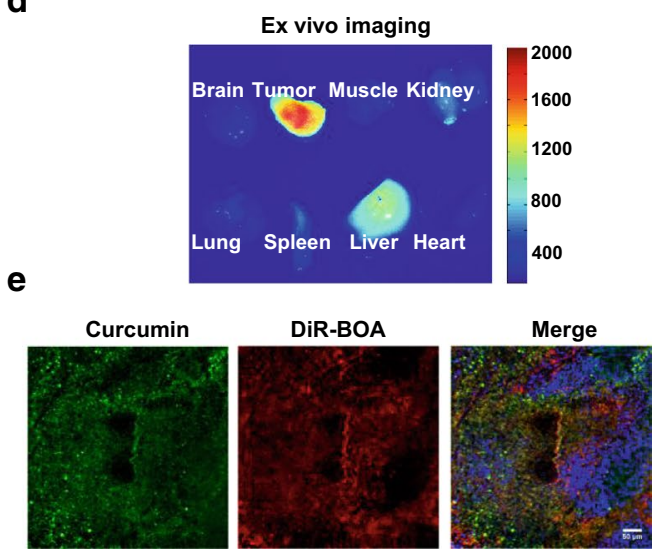

Fig. 4 Evaluation of Cur targeted delivery of Cur@a-NTP-LNs in vivo. a UV-visible absorption spectrum of Cur(DiR-BOA)@a-NTP-LNs, free Cur, and free DiR-BOA in PBS solution at room temperature. b Blood circulation of Cur(DiR-BOA)@a-NTP-LNs in normal nude mice $(n=5)$. $\mathbf{c}$ Whole-body imaging of 5-8F tumor-bearing mice at 24 and $48 \mathrm{~h}$ after intravenous injection of Cur(DiR-BOA)@a-NTP-LNs. d ex vivo images of the tumor and normal organs (brain, muscle, kidney, lung, spleen, liver, and heart) after imaging. e Confocal imaging analysis of the co-localization of Cur (Green) and DiR-BOA (Red) in tumor sections pre-stained with DAPI (blue) before multispectral microscopy. Scale bar $=50 \mu \mathrm{m}$. Results are presented as mean \pm s.d 
$7.2 \mathrm{~h}$ (Fig. 4b). Thus, the loading of Cur into $\alpha$-NTPLNs did not affect its in vivo pharmacokinetics.

After intravenous injection of Cur(DiR-BOA)@ $\alpha-$ NTP-LNs into 5-8F tumor-bearing mice, the fluorescence signals of DiR-BOA were monitored with a homemade whole-body fluorescence imaging system. Fluorescence signals at the tumor sites at $24 \mathrm{~h}$ postinjection were observed and gradually increased with time due to the selective accumulation of Cur(DiRBOA)@ $\alpha-N T P-L N s$ in the tumor regions (Fig. 4c). The ex vivo fluorescence evaluation of the dissected tumors and normal tissues (brain, muscle, kidney, lung, spleen, liver, and heart) showed strong NIR fluorescence signals in the tumor region in Cur(DiR-BOA)@ $\alpha$-NTPLNs-treated group (Fig. 4d). Confocal imaging of the frozen tumor slices from the Cur(DiR-BOA)@ $\alpha-N T P-$ $\mathrm{LN}$-treated group displayed strong fluorescence signals of Cur and DiR-BOA, demonstrating that Cur@ $\alpha-N T P-$ LNs penetrated the solid 5-8F tumors and efficiently delivered Cur into the tumor site (Fig. 4e).

\section{Cur@a-NTP-LNs inhibited the growth of 5-8F tumors in vivo}

5-8F subcutaneous tumor-bearing mice were prepared and randomly divided into four groups on day 13 from the injection of 5-8F tumor cells to evaluate the therapeutic efficacy of Cur@ $\alpha-N T P-L N s$ on NPC tumors. Mice with a tumor volume of over $20 \mathrm{~mm}^{3}$ were intravenously injected with PBS or $125 \mathrm{nmol}$ free Cur, Cur@ $\alpha-N T P-L N s$, or peptide equivalent $\alpha$-NTP-LNs on day 13, and the intravenous injection was repeated every other day for 5 times (Fig. 5a). The tumor volume in the PBS-treated group on day 25 almost reached $1500 \mathrm{~mm}^{3}$ endpoint, and the mice were euthanized for humane reasons. The mean tumor volumes on day 29 were significantly different among Cur-treated group $\left(1187 \pm 145.8 \mathrm{~mm}^{3}\right)$, $\alpha$-NTP-LNs-treated group $\left(660 \pm 343 \mathrm{~mm}^{3}\right)$, and Cur@ $\alpha-\mathrm{NTP}-\mathrm{LNs}$-treated group $\left(348 \pm 133 \mathrm{~mm}^{3}\right)(\mathrm{n}=5, p<0.001$, Fig. $5 \mathrm{~b})$. The growth of 5-8F tumors was inhibited by Cur@ $\alpha-N T P-L N s$, with more than $71 \%$ and $47 \%$ inhibition relative to Curand $\alpha$-NTP-LNs-treated control groups, respectively, suggesting a synergistically enhanced NPC-specific
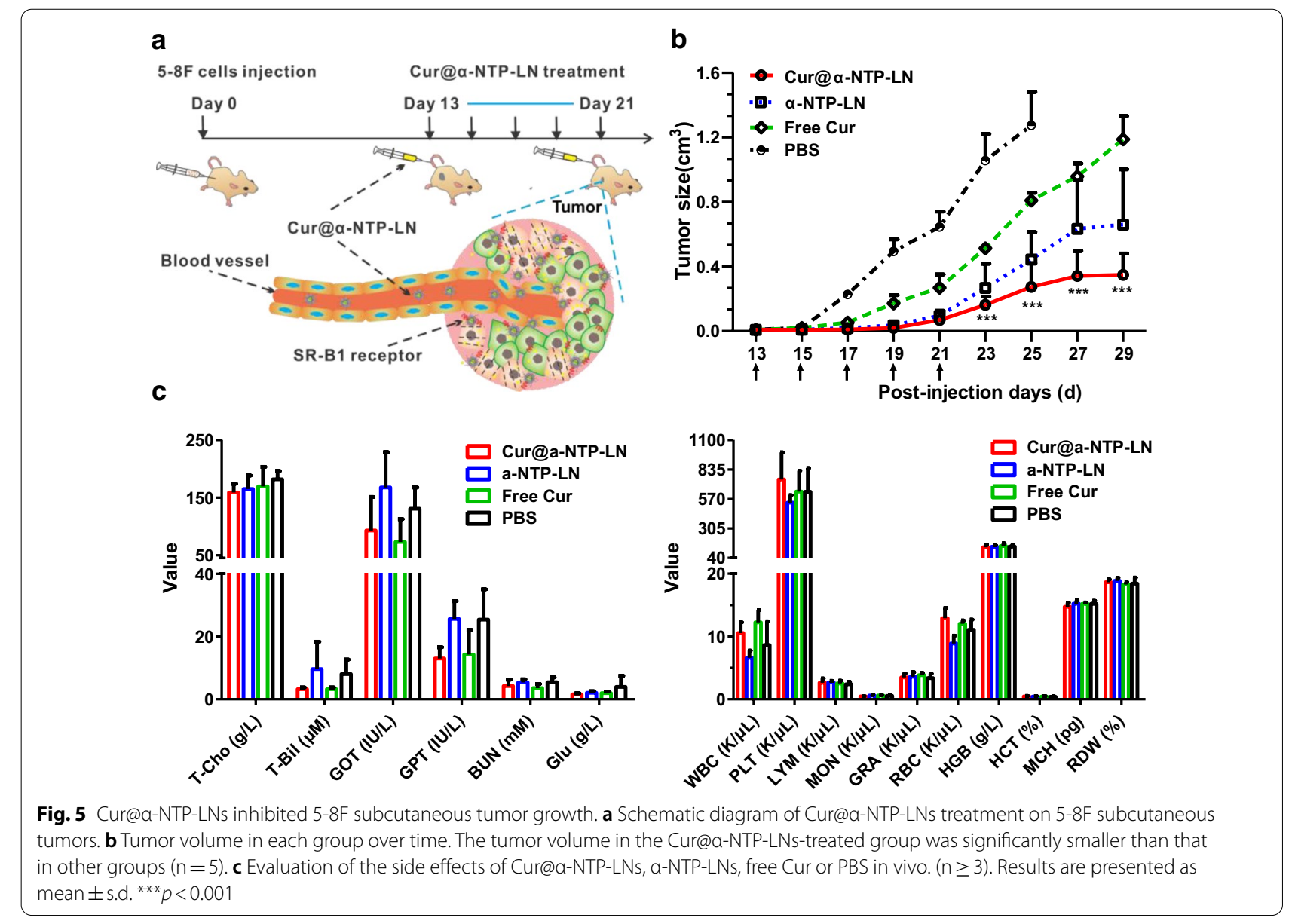
anti-cancer effects of Cur@ $\alpha-N T P-L N s$ on tumor growth.

Blood was collected on days 25 and 29 from 5-8F cell injection for hemanalysis and biochemical analysis to evaluate the toxicological potential of Cur@ $\alpha-N T P-$ LNs. Figure $5 \mathrm{c}$ shows no statistically significant differences in the hepatic and renal function [e.g. aspartate aminotransferase (GOT), alanine aminotransferase (GPT), glucose (Glu), urea nitrogen (BUN), total cholesterol (T-Cho), and total bilirubin (T-Bil)], and hemanalysis parameters [e.g. white blood cells (WBC), blood platelets (PLT), leukocytes (LYM), monocytes (MON), granulocytes (GRA), red blood cells (RBC), hemoglobin (HGB), hematocrit (HCT), and corpuscular hemoglobin $(\mathrm{MCH})$, and red blood cell volume distribution width $(\mathrm{RDW})]$ among the four treatment groups (5 mice per group). Thus, no noticeable side effects occurred after the systemic administration of Cur@ $\alpha$ NTP-LNs, providing a potential use of Cur@ $\alpha-N T P-$ LNs as an effective and safe therapeutic agent for the therapy to cure NPC.

\section{Cur@a-NTP-LNs delayed NPC lung metastasis}

$5-8 \mathrm{~F}$ cells were intravenously injected into mice to detect the ability of Cur@ $\alpha-N T P-L N s$ to inhibit pulmonary metastases, and the mice were randomly divided into 4 groups and treated with an intravenous injection of PBS or $125 \mathrm{nmol}$ free Cur, Cur@ @-NTP-LNs or peptide equivalent $\alpha$-NTP-LNs through the tail vein. The treatments were performed on day 13, 15, 17, 19, and 21 after 5-8F cell injection (Fig. 6a). Three mice in free Cur, Cur@ $\alpha-N T P-L N s-$ and $\alpha$-NTP-LNs-treated groups were separately used to perform an X-ray computed tomography $(\mathrm{CT})$ scan on day 25 . Axial CT scan results revealed the presence of large and numerous lung metastases in PBS- and free Cur-treated mice, small pulmonary nodules of various sizes in $\alpha$-NTP-LNs-treated mice, and no significant difference with the lung of normal mice in the Cur@ $\alpha-N T P-L N s-t r e a t e d$ mice (Fig. 6b). The mice were sacrificed after the confirmation of the presence of metastases by CT, and sections of lung tissues were stained with H\&E to evaluate lung metastasis. The H\&E images showed apparent primary malignancies in PBS

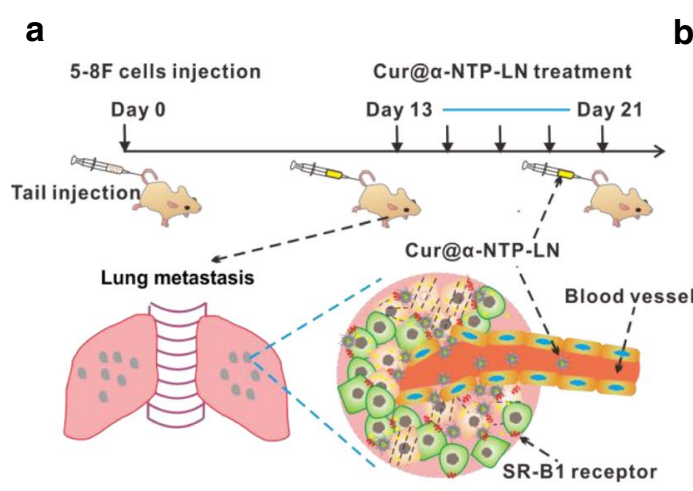

b

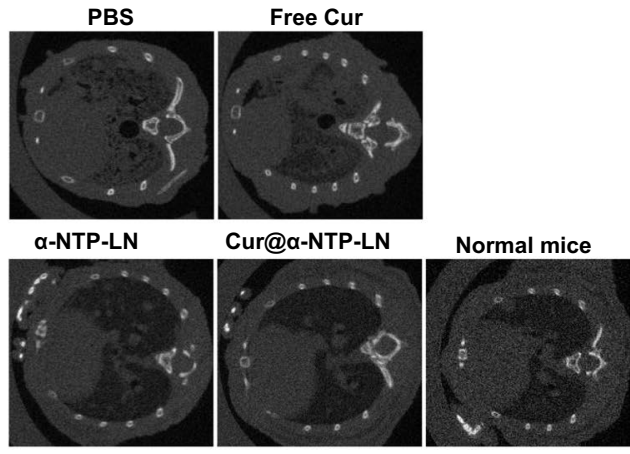

C

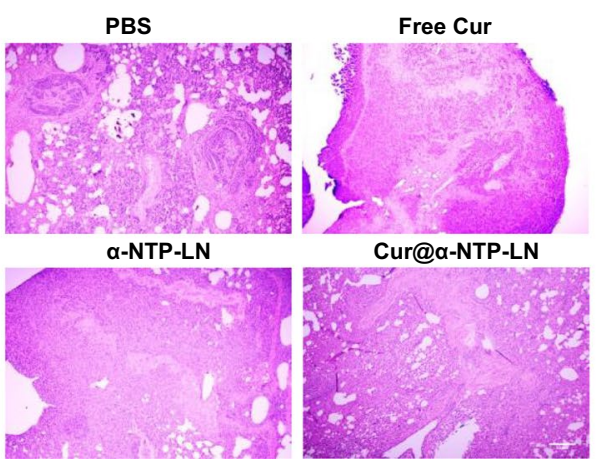

d

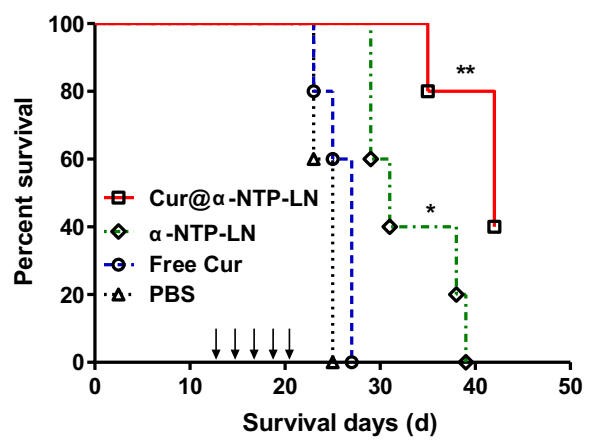

Fig.6 Cur@a-NTP-LNs delayed the progression of NPC lung metastasis. a Schematic diagram of Cur@a-NTP-LNs treatment on NPC lung metastasis. b X-ray computed tomography scan for the detection of pulmonary metastases in normal mice and mice after treatment with PBS or 125 nmol of free Cur, Cur equivalent Cur@a-NTP-LNs or peptide equivalent a-NTP-LNs at day 25 after 5-8F cell injection. c Histopathological analyses of H\&E-stained lung tissues from mice treated with Cur@a-NTP-LNs, a-NTP-LNs, Cur or PBS at day 25 after 5-8F cell injection. Scale bar=50 $\mu$ m. d Survival curve of mice with NPC lung metastases after treatment with PBS or 125 nmol free Cur, Cur equivalent Cur@a-NTP-LNs or peptide equivalent a-NTP-LNs $(n=5)$ 
control mice, plenty of macroscopic malignant nodules in Cur-treated mice, and few macroscopic malignant nodules in $\alpha$-NTP-LNs-treated mice (Fig. 6c), indicating that Cur@ $\alpha-N T P-L N s$ efficiently inhibited NPC lung metastasis.

Next, an NPC lung metastasis model was prepared to further investigate the therapeutic efficacy of Cur@ $\alpha$ NTP-LNs in the treatment of NPC lung metastasis by the injection of mRFP-5-8F cells on the tail vein of athymic nude mice $(\mathrm{nu} / \mathrm{nu})$. An amount of $125 \mathrm{nmol}$ free Cur, Cur@ $\alpha-N T P-L N s$ or peptide equivalent $\alpha$-NTP-LNs were injected at day 13 after the injection of mRFP-5-8F cells, and the treatment experiments were started on days $13,15,17,19$, and 21 . All mice were sacrificed on day 35 , and fluorescent imaging was performed. The wholebody fluorescence imaging revealed that lung metastases only occurred in the Cur-treated group (Additional file 1: Fig. S5a). Lung tissues in all treated mice were exposed and imaged under red fluorescence illumination. Red fluorescence images showed that small lung metastases were easily visible and detected in the Cur-treated group, whereas fluorescence signals in the Cur@ $\alpha-N T P-$ LNs- and $\alpha$-NTP-LNs-treated group were almost negligible (Additional file 1: Fig. S5b). H\&E staining of lung tissues was performed to verify the inhibitory effect of Cur@ $\alpha-N T P-L N s$ and $\alpha$-NTP-LNs on lung metastasis. The necropsy results showed plenty of malignant nodules in Cur-treated mice and few macroscopic malignant nodules in the $\alpha$-NTP-LNs-treated mice, while no malignant nodules were detected in Cur@ $\alpha$-NTP-LNs-treated mice (Additional file 1: Fig. S5c). These results showed that Cur@ $\alpha-N T P-L N s$ exerted synergistic enhanced inhibitory effect on NPC lung metastasis compared to free Cur and $\alpha$-NTP-LNs.

5-8F lung metastatic mice models were prepared and monitored on day 27 after 5-8F cell injection and different treatments to evaluate the effect of Cur@ $\alpha-N T P-L N s$ on survival rates. All the PBS-treated control mice $(n=5)$ and free Cur-treated mice $(\mathrm{n}=5)$ died, whereas $\alpha$-NTPLNs- and Cur@ $\alpha-N T P-L N s-t r e a t e d$ mice were alive $(\mathrm{n}=5, p<0.05$, Fig. 6d). In addition, 60\% of the Cur@ $\alpha-$ NTP-LNs-treated mice were still alive at day 42 after cell injection, and all the other treated mice were dead $(n=5$, $p<0.01$, Fig. 6d). These results revealed that Cur@ $\alpha-$ NTP-LNs significantly delayed the development of lung metastases from NPC cells and extended the survival rate of the mice compared to $\alpha$-NTP-LNs and free Cur.

\section{Discussion}

Cur is a phytochemical compound extracted from the rhizome of turmeric, with a remarkable therapeutic potential in the treatment of NPC [27, 28]. Extensive preclinical and clinical studies in the past decades have indicated the therapeutic effects of Cur in curing cancer $[15,29]$. Some proof-of-concept studies demonstrated that Cur efficiently sensitizes NPC cells to chemotherapeutic agents and radiation therapy [28, 30]. Research studies proved that Cur not only suppresses cell proliferation, metastasis, and tumor angiogenesis, but also induces cell apoptosis through the modulation of different molecular targets [31, 32]. However, fast systemic elimination and low bioavailability hinder its clinical application [33]. The incorporation of Cur into nanoparticles can enhance its bioavailability at the tumor sites through a passive or active mechanism, being beneficial for patients [15]. This study focused on the development of a targeted Cur nanoparticle formulation to treat advanced NPC.

Cur was encapsulated into $\alpha$-NTP-LNs to form a new sub-30 nm NPC-targeting therapeutic lipid nanoparticle Cur@ $\alpha-\mathrm{NTP}-\mathrm{LNs}$, which combined the NPCspecific therapeutic effects of $\alpha$-NTP-LNs with the cancer chemopreventive effects of Cur. $\alpha$-NTP-LNs exhibit SR-B1 targeting, abundantly expressed in 5-8F cells, and exerts cytotoxicity through the induction of apoptosis and autophagy [20]. However, flow cytometry analysis showed that Cur@ $\alpha-N T P-L N s$ not only keep the ability to target SR-B1 but also exerted a synergistically enhanced suppression of 5-8F cell proliferation, motility, and colony formation compared to free Cur and $\alpha$-NTPLNs (Fig. 3). Furthermore, Cur@ $\alpha-N T P-L N s$ achieved over $71 \%$ and $47 \%$ inhibitory effect on $5-8 \mathrm{~F}$ tumor growth when compared to free Cur and $\alpha-\mathrm{NTP}-\mathrm{LNs}$ respectively, confirming that Cur@ $\alpha-N T P-L N s$ with its combined anti-cancer activity of $\alpha$-NTP-LNs and Cur synergistically inhibited NPC tumor growth (Fig. 5). The substantially improved therapeutic effects of Cur@ $\alpha-N T P-L N s$ in vivo might be attributable to the synergistic inhibition of tumor cell growth and tumor angiogenesis because the higher inhibitory effect of Cur@ @-NTP-LNs than that of $\alpha$-NTP-LNs on tumor growth was observed on day 23 after 5-8F cells implantation (Fig. 5). Cur@ $\alpha-N T P-L N s$ used in the $5-8 \mathrm{~F}$ lung metastasis models showed significantly improved survival rates compared to those of $\alpha$-NTP-LNs, which further confirmed its synergistically enhanced suppression on tumor growth and angiogenesis (Fig. 6). Additionally, Cur@ @-NTP-LNs treatment did not cause any detectable damage to liver and kidney function and cell membrane of RBCs, as revealed by hemanalysis and biochemical analysis (Fig. 5). These properties might encourage the further development of Cur@ $\alpha-N T P-L N s$ formulations for the preclinical application of NPC-specific targeted delivery.

Free Cur could be loaded into the hydrophobic core of $\alpha$-NTP-LNs thanks to the lipophilic property of curcumin, which not only increased its aqueous solubility 
and stability, but also protected its bioactivity during the in vivo delivery of cancer therapeutics. The spontaneous oxidative degradation of Cur is also a primary factor contributing to its low bioavailability[34]. Curcumin undergoes autoxidation very easily, inactivated by peroxidases and oxidizing agents, and degradation at physiological conditions [35]. Cur exerts its anti-cancer effect through oxidative degradation to modulate reactive oxygen species (ROS) generation [36]. Most conventional nanoparticles lack ROS scavenging properties and cannot protect Cur from ROS-mediated oxidative degradation $[15,37]$. $\alpha$-NTP-LNs were composed of amphipathic $\alpha$-helical peptides, and the amphipathic apoA-I mimetic peptide exerts anti-cancer effect as a direct scavenger of ROS [38, 39]. Thus, Cur@ $\alpha-N T P-L N s$ might protect the encapsulated Cur from oxidative degradation, improve its poor bioavailability and increase its tumor-targeting ability via targeted delivery.

Various Cur nanoformulations have been developed based on dispersed or precipitation processes for the accurate cancer imaging and effective treatment [40]. Although these nanoparticles confer many advantages over that of free chemotherapeutic agents, the lack of tissue specificity is still the main drawback of chemotherapy because most reported Cur nanoparticles can only passively accumulate in the tumor site via enhanced permeability and retention (EPR) effect [36]. Nanoparticles presenting targeting moieties (e.g. antibodies, peptides, or nucleic acid/aptamers) on the surface can achieve high targeting specificity, while avoiding non-specificity binding [36, 41]. Murali et al. conjugated PSMA whole antibody to PLGA-CUR nanoparticle for the targeted delivery of Cur to prostate cancer [42]. However, the batch-to-batch reproducibility and in vivo toxicity of conventional Cur nanoparticles may curb their clinical translation. Our Cur@ $\alpha-N T P-L N s$ nanoformulation was generated with a simple and robust approach and did not exert detectable toxicity in vivo, being potentially promising in the treatment of NPC and its distant metastases in clinical practice. Furthermore, the ultra-small biocompatible nanoparticles loading tumor antigen peptides revealed an enhancement of antigen presentation by dendritic cells through the SR-B1 pathway [43-45]. Future studies with combined delivery of chemotherapeutic agents with imaging contrast agents, tumor-specific antigenic peptides or antibody fragments in a single $\alpha$-NTPLNs nanoparticle could reveal the potentially more effective way of treating NPC.

\section{Conclusions}

In conclusion, a sub-30 nm biocompatible lipid nanoparticle Cur@ $\alpha-N T P-L N s$ was constructed, exhibiting SR-B1 targeting ability and synergistically enhanced inhibitory effect on NPC tumor growth and its metastasis. The newly formed nanoparticles Cur@ $\alpha-N T P-L N s$ successfully encapsulated Cur to increase its solubility, and its specifically deliver into the center of solid NPC tumors, with enhanced anti-cancer activities due to its ultra-small size. Furthermore, our results showed that Cur@ $\alpha-N T P-L N s$ were not only effective in targeting NPC cells, suppressing cellular proliferation, and inducing cell apoptosis in vitro, but also exhibited a remarkable inhibitory effect on NPC tumors and their metastasis in vivo. Thus, the overall experimental evidence suggested that Cur@ $\alpha-N T P-L N s$ formulation might be an excellent promise for the preclinical treatment of NPC tumors due to its low toxicity and prominent therapeutic effects.

\section{Supplementary Information}

The online version contains supplementary material available at https://doi. org/10.1186/s12951-021-00966-6.

Additional file 1: Figure S1. Particle size distribution of Cur@a-NTP-LNs. Dynamic light scattering (DLS) measurement showing the intensity weighted particle size of Cur@a-NTP-LNs that varied from 15.2 to 119.8 $\mathrm{nm}$ with the increasing amount of a-NTP peptide. Figure S2. Excitation and emission spectra of free curcumin in PBS solution at room temperature. Figure S3. Inhibition of the proliferation of 5-8F cells treated with PBS, $50 \mu \mathrm{M}$ free Cur, Cur equivalent Cur@a-NTP-LNs, or peptide equivalent a-NTP-LNs $(100 \mu \mathrm{M})$ at $24 \mathrm{~h}$. Scale bar $=100 \mu \mathrm{m}$. Figure S4. Semi-native SDS-PAGE assay and fluorescence imaging to evaluate the stability of Cur(DiR-BOA)@a-NTP-LNs. Figure S5. Anti-cancer effects of Cur@a-NTP-LNs on mRFP-5-8F lung metastasis. (a) Overlay of bright field and color fluorescence images showing mRFP-5-8F tumor metastasis that occurred in free Cur-treated mice but undetectable in both Cur@a-NTPLNs- and a-NTP-LNs-treated mice by necropsy. (b) Fluorescence imaging of lung tissues collected from mice in a. (c) Histopathological analyses of H\&E-stained lung tissues from mice treated with $135 \mathrm{nmol}$ free Cur, Cur equivalent Cur@a-NTP-LNs or peptide equivalent a-NTP-LNs at day 35 after mRFP-5-8F cell injection. Scale bar $=30 \mu \mathrm{m}$.

\section{Acknowledgements}

We thank Prof. Mu-Sheng Zeng of the Sun Yat-sen University Cancer Center for providing nasopharyngeal cancer cell line 5-8F cells. We also thank the Optical Bioimaging Core Facility and the Center for Nanoscale Characterization \& Devices (CNCD) of WNLO-HUST for the support in data acquisition and the Analytical and Testing Center of HUST for spectral measurements.

\section{Authors' contributions}

$L H$ and $Z Z$ conceived the idea and designed the experiments; $L H, L L, L N, L Q$, and $Y X$ performed the experiments. LH drafted the manuscript. All authors read and approved the final manuscript.

\section{Funding}

This work was supported by the National Science Fund for Distinguished Young Scholars (81625012 from ZZ), the National Natural Science Foundation of China (81971025 from LH), the Program for HUST Academic Frontier Youth Team (ZZ), and the Innovation Fund of WNLO (ZZ). 


\section{Declarations}

Ethics approval and consent to participate

All procedures involving experimental animals were carried out under guidelines approved by the Institutional Animal Care and Use Committee of Huazhong University of Science and Technology.

\section{Consent for publication}

Not applicable.

\section{Competing interests}

The authors declare no conflict of interest, financial or otherwise.

\section{Author details}

${ }^{1}$ Britton Chance Center for Biomedical Photonics, Wuhan National Laboratory for Optoelectronics-Huazhong University of Science and Technology, Wuhan 430074, China. ${ }^{2}$ MoE Key Laboratory for Biomedical Photonics, Department of Biomedical Engineering, Huazhong University of Science and Technology, Wuhan 430074, China.

\section{Received: 24 March 2021 Accepted: 19 July 2021}

Published online: 28 July 2021

\section{References}

1. McDermott AL, Dutt SN, Watkinson JC. The aetiology of nasopharyngeal carcinoma. Clin Otolaryngol Allied Sci. 2001;26:82-92.

2. Wei WI, Sham JS. Nasopharyngeal carcinoma. Lancet. 2005;365:2041-54.

3. Lee AW, Ma BB, Ng WT, Chan AT. Management of nasopharyngeal carcinoma: current practice and future perspective. J Clin Oncol. 2015:33:3356-64.

4. Blagosklonny MV. Prospective strategies to enforce selectively cell death in cancer cells. Oncogene. 2004;23:2967-75.

5. Heslop HE. Combining drugs and biologics to treat nasopharyngeal cancer. Mol Ther. 2014;22:8-9.

6. Spratt DE, Lee N. Current and emerging treatment options for nasopharyngeal carcinoma. Onco Targets Ther. 2012;5:297-308.

7. Luo H, Hong H, Yang SP, Cai W. Design and applications of bispecific heterodimers: molecular imaging and beyond. Mol Pharm. 2014;11:1750-61.

8. Luo H, Hernandez R, Hong H, Graves SA, Yang Y, England CG, Theuer CP, Nickles RJ, Cai W. Noninvasive brain cancer imaging with a bispecific antibody fragment, generated via click chemistry. Proc Natl Acad Sci U S A. 2015;112:12806-11.

9. Sharifi-Rad J, Rayess YE, Rizk AA, Sadaka C, Zgheib R, Zam W, Sestito S, Rapposelli S, Neffe-Skocinska K, Zielinska D, et al. Turmeric and its major compound curcumin on health: bioactive effects and safety profiles for food, pharmaceutical biotechnological and medicinal applications. Front Pharmacol. 2020;11:01021.

10. Tomeh MA, Hadianamrei $R$, Zhao X. A review of curcumin and its derivatives as anticancer agents. Int J Mol Sci. 2019;20(5):1033.

11. Patra JK, Das G, Fraceto LF, Campos EVR, Rodriguez-Torres MDP, AcostaTorres LS, Diaz-Torres LA, Grillo R, Swamy MK, Sharma S, et al. Nano based drug delivery systems: recent developments and future prospects. J Nanobiotechnology. 2018;16:71.

12. Zheng P, Ding B, Shi R, Jiang Z, Xu W, Li G, Ding J, Chen X. A multichannel $\mathrm{Ca}(2+)$ nanomodulator for multilevel mitochondrial destruction-mediated cancer therapy. Adv Mater. 2021;33:e2007426.

13. Zheng P, Ding B, Jiang Z, Xu W, Li G, Ding J, Chen X. Ultrasound-augmented mitochondrial calcium ion overload by calcium nanomodulator to induce immunogenic cell death. Nano Lett. 2021;21:2088-93.

14. Yallapu MM, Jaggi M, Chauhan SC. Curcumin nanoformulations: a future nanomedicine for cancer. Drug Discov Today. 2012;17:71-80.

15. Naksuriya O, Okonogi S, Schiffelers RM, Hennink WE. Curcumin nanoformulations: a review of pharmaceutical properties and preclinical studies and clinical data related to cancer treatment. Biomaterials. 2014;35:3365-83

16. Ghalandarlaki N, Alizadeh AM, Ashkani-Esfahani S. Nanotechnologyapplied curcumin for different diseases therapy. Biomed Res Int. 2014;2014:394264.
17. Wei L, Chen J, Ding J. Sequentially stimuli-responsive anticancer nanomedicines. Nanomedicine (Lond). 2021;16:261-4.

18. Chen J, Jiang Z, Xu W, Sun T, Zhuang X, Ding J, Chen X. Spatiotemporally targeted nanomedicine overcomes hypoxia-induced drug resistance of tumor cells after disrupting neovasculature. Nano Lett. 2020;20:6191-8.

19. Cabral H, Matsumoto Y, Mizuno K, Chen Q, Murakami M, Kimura M, Terada Y, Kano MR, Miyazono K, Uesaka M, et al. Accumulation of sub-100 nm polymeric micelles in poorly permeable tumours depends on size. Nat Nanotechnol. 2011;6:815-23.

20. Luo H, Lu L, Yang F, Wang L, Yang X, Luo Q, Zhang Z. Nasopharyngeal cancer-specific therapy based on fusion peptide-functionalized lipid nanoparticles. ACS Nano. 2014;8:4334-47.

21. Corbin IR, Chen J, Cao W, Li H, Lund-Katz S, Zheng G. Enhanced cancertargeted delivery using engineered high-density lipoprotein-based nanocarriers. J Biomed Nanotechnol. 2007;3:367-76.

22. Zhang Z, Chen J, Ding L, Jin H, Lovell JF, Corbin IR, Cao W, Lo PC, Yang M, Tsao MS, et al. HDL-mimicking peptide-lipid nanoparticles with improved tumor targeting. Small. 2010;6:430-7.

23. Yang X, Gong H, Fu J, Quan G, Huang C, Luo Q. Molecular imaging of small animals with fluorescent proteins: from projection to multimodality. Comput Med Imaging Graph. 2012;36:259-63.

24. Xiong T, Zhang Z, Liu BF, Zeng S, Chen Y, Chu J, Luo Q. In vivo optical imaging of human adenoid cystic carcinoma cell metastasis. Oral Oncol. 2005:41:709-15.

25. Zheng Y, Liu Y, Jin H, Pan S, Qian Y, Huang C, Zeng Y, Luo Q, Zeng M, Zhang Z. Scavenger receptor $B 1$ is a potential biomarker of human nasopharyngeal carcinoma and its growth is inhibited by HDL-mimetic nanoparticles. Theranostics. 2013;3:477-86.

26. Dobson PD, Kell DB. Carrier-mediated cellular uptake of pharmaceutical drugs: an exception or the rule? Nat Rev Drug Discov. 2008;7:205-20.

27. Lin YT, Wang LF, Hsu YC. Curcuminoids suppress the growth of pharynx and nasopharyngeal carcinoma cells through induced apoptosis. J Agric Food Chem. 2009:57:3765-70.

28. Xie YQ, Wu XB, Tang SQ. Curcumin treatment alters ERK-1/2 signaling in vitro and inhibits nasopharyngeal carcinoma proliferation in mouse xenografts. Int J Clin Exp Med. 2014;7:108-14.

29. Dhillon N, Aggarwal BB, Newman RA, Wolff RA, Kunnumakkara AB, Abbruzzese JL, Ng CS, Badmaev V, Kurzrock R. Phase II trial of curcumin in patients with advanced pancreatic cancer. Clin Cancer Res. 2008:14:4491-9.

30. Yang J, Zhu D, Liu S, Shao M, Liu Y, Li A, Lv Y, Huang M, Lou D, Fan Q. Curcumin enhances radiosensitization of nasopharyngeal carcinoma by regulating circRNA network. Mol Carcinog. 2020;59:202-14.

31. Kunnumakkara AB, Anand P, Aggarwal BB. Curcumin inhibits proliferation, invasion, angiogenesis and metastasis of different cancers through interaction with multiple cell signaling proteins. Cancer Lett. 2008:269:199-225.

32. Hassan FU, Rehman MS, Khan MS, Ali MA, Javed A, Nawaz A, Yang C. Curcumin as an alternative epigenetic modulator: mechanism of action and potential effects. Front Genet. 2019;10:514

33. Hatcher H, Planalp R, Cho J, Torti FM, Torti SV. Curcumin: from ancient medicine to current clinical trials. Cell Mol Life Sci. 2008;65:1631-52.

34. Alemi A, Zavar Reza J, Haghiralsadat F, Zarei Jaliani H, Haghi Karamallah M Hosseini SA, Haghi Karamallah S. Paclitaxel and curcumin coadministration in novel cationic PEGylated niosomal formulations exhibit enhanced synergistic antitumor efficacy. J Nanobiotechnology. 2018;16:28.

35. Ketron AC, Gordon ON, Schneider C, Osheroff N. Oxidative metabolites of curcumin poison human type II topoisomerases. Biochemistry. 2013;52:221-7.

36. Thangavel S, Yoshitomi T, Sakharkar MK, Nagasaki Y. Redox nanoparticles inhibit curcumin oxidative degradation and enhance its therapeutic effect on prostate cancer. J Control Release. 2015;209:110-9.

37. Chung SH, Mehta R, Tromberg BJ, Yodh AG. Non-invasive measurement of deep tissue temperature changes caused by apoptosis during breast cancer neoadjuvant chemotherapy: a case study. J Innov Opt Health Sci. 2011:4:361-72

38. Gordon SM, Davidson WS. Apolipoprotein A-I mimetics and highdensity lipoprotein function. Curr Opin Endocrinol Diabetes Obes. 2012;19:109-14.

39. Ganapathy E, Su F, Meriwether D, Devarajan A, Grijalva V, Gao F, Chattopadhyay A, Anantharamaiah GM, Navab M, Fogelman AM, et al. D-4F, 
an apoA-I mimetic peptide, inhibits proliferation and tumorigenicity of epithelial ovarian cancer cells by upregulating the antioxidant enzyme MnSOD. Int J Cancer. 2012;130:1071-81.

40. Piktel E, Niemirowicz K, Watek M, Wollny T, Deptula P, Bucki R. Recent insights in nanotechnology-based drugs and formulations designed for effective anti-cancer therapy. J Nanobiotechnology. 2016;14:39.

41. Yang D, Feng L, Dougherty CA, Luker KE, Chen D, Cauble MA, Banaszak Holl MM, Luker GD, Ross BD, Liu Z, Hong H. In vivo targeting of metastatic breast cancer via tumor vasculature-specific nano-graphene oxide. Biomaterials. 2016;104:361-71.

42. Yallapu MM, Khan S, Maher DM, Ebeling MC, Sundram V, Chauhan N, Ganju A, Balakrishna S, Gupta BK, Zafar N, et al. Anti-cancer activity of curcumin loaded nanoparticles in prostate cancer. Biomaterials. 2014:35:8635-48
43. Qian Y, Jin H, Qiao S, Dai Y, Huang C, Lu L, Luo Q, Zhang Z. Targeting dendritic cells in lymph node with an antigen peptide-based nanovaccine for cancer immunotherapy. Biomaterials. 2016;98:171-83.

44. Jin H, Qian Y, Dai Y, Qiao S, Huang C, Lu L, Luo Q, Chen J, Zhang Z. Magnetic enrichment of dendritic cell vaccine in lymph node with fluorescent-magnetic nanoparticles enhanced cancer immunotherapy. Theranostics. 2016;6:2000-14

45. Li L, Ma B, Wang W. Peptide-based nanomaterials for tumor immunotherapy. Molecules. 2020;26(1):132.

\section{Publisher's Note}

Springer Nature remains neutral with regard to jurisdictional claims in published maps and institutional affiliations.
Ready to submit your research? Choose BMC and benefit from:

- fast, convenient online submission

- thorough peer review by experienced researchers in your field

- rapid publication on acceptance

- support for research data, including large and complex data types

- gold Open Access which fosters wider collaboration and increased citations

- maximum visibility for your research: over 100M website views per year

At BMC, research is always in progress.

Learn more biomedcentral.com/submissions 